\title{
Thermal fatigue testing of a diffusion-bonded beryllium divertor mock-up under ITER relevant conditions
}

\author{
D.L. Youchison, ${ }^{a}$ R. Guiniiatouline, ${ }^{b}$ R.D. Watson, J.M. McDonald, B.E. Mills and D.R. Boehme \\ aPennsylvania State University, Nuclear Engineering Department \\ 231 Sackett Bldg., University Park, PA 16802, USA \\ bD.V. Efremov Scientific Research Institute of Electrophysical Apparatus OCT $2 / 1995$ \\ St. Petersburg, 189631 Russian Federation \\ Sandia National Laboratories \\ P.O. Box 5800 Albuquerque, New Mexico 87185-1129, USA

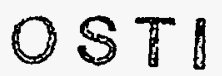

Thermal response and thermal fatigue tests of four $5 \mathrm{~mm}$ thick beryllium tiles on a Russian divertor mock-up were completed on the Electron Beam Test System at Sandia National Laboratories. The beryllium tiles were diffusion bonded onto an OFHC copper saddleblock and a DSCu (MAGT) tube containing a porous coating. Thermal response tests were performed on the tiles to an absorbed heat flux of $5 \mathrm{MW} / \mathrm{m}^{2}$ and surface temperatures near $300^{\circ} \mathrm{C}$ using 1.4 $\mathrm{MPa}$ water at $5.0 \mathrm{~m} / \mathrm{s}$ flow velocity and an inlet temperature of $8-15^{\circ} \mathrm{C}$. One tile was exposed to incrementally increasing heat fluxes up to $9.5 \mathrm{MW} / \mathrm{m}^{2}$ and surface temperatures up to $690^{\circ} \mathrm{C}$ before debonding at $10 \mathrm{MW} / \mathrm{m}^{2}$. A third tile debonded after 9200 thermal fatigue cycles at 5 $\mathrm{MW} / \mathrm{m}^{2}$, while another debonded after 6800 cycles. In all cases, fatigue failure occurred in the intermetallic layers between the beryllium and copper. No fatigue cracking of the bulk beryllium was observed. During thermal cycling, a gradual loss of porous coating produced increasing sample temperatures. These experiments indicate that diffusion-bonded beryllium tiles can survive several thousand thermal cycles under ITER relevant conditions without failure. However, the reliability of the diffusion bonded joint remains a serious issue.

\section{INTRODUCTION}

The current reference design for the ITER divertor specifies 5 to $10 \mathrm{~mm}$ thick beryllium tiles bonded to an actively cooled CuCrZr substrate. This duplex structure must handle a cyclic heat flux of $5 \mathrm{MW} / \mathrm{m}^{2}$ approximately $1000 \mathrm{~s}$ in duration for 10000 cycles. Active cooling must limit the beryllium surface temperature to between 500 and $700{ }^{\circ} \mathrm{C}$ while using water inlet temperatures near $150{ }^{\circ} \mathrm{C}$ to maintain beryllium in its ductile range.

There are two areas of critical concern for the divertor from a high heat flux perspective. The first is the survivability of the beryllium armor under cyclic thermal loading at 5 $\mathrm{MW} / \mathrm{m}^{2}$. Due to its low ductility, beryllium can experience lateral cracking which can impede the thermal conduction to the cooled substrate. The second is the reliability of the thermal bond to the cooled substrate under cyclic loading. Various bonding techniques, such as brazing, diffusion bonding, roll bonding, electroplating and friction welding are currently being studied to join beryllium to copper [1-3]. High thermally-induced stresses occur in the bond between beryllium and copper because of differences in the thermal expansion and the elastic modulus. If the bond strength is less than the thermal shear stress, the bond may fail completely. Diffusion bonding can produce joints with strengths close to the base metal [4].

This article reports on the use of diffusion

\footnotetext{
${ }^{\star}$ Research sponsored by the Office of Fusion Energy, U.S. Department of Energy, under contract DE-AC04-94AL85000 with Martin Marietta Energy Systems, Inc.
} 


\section{DISCLAIMER}

This report was prepared as an account of work sponsored by an agency of the United States Government. Neither the United States Government nor any agency thereof, nor any of their employees, make any warranty, express or implied, or assumes any legal liability or responsibility for the accuracy, completeness, or usefulness of any information, apparatus, product, or process disclosed, or represents that its use would not infringe privately owned rights. Reference herein to any specific commercial product, process, or service by trade name, trademark, manufacturer, or otherwise does not necessarily constitute or imply its endorsement, recommendation, or favoring by the United States Government or any agency thereof. The views and opinions of authors expressed herein do not necessarily state or reflect those of the United States Government or any agency thereof. 


\section{DISCLAIMER}

Portions of this document may be illegible in electronic image products. Images are produced from the best available original document. 
bonded beryllium as an actively cooled PFC under ITER relevant conditions. High heat flux testing of a flat tile beryllium divertor mock-up was performed using the $30 \mathrm{~kW}$ Electron Beam Test System (EBTS) at Sandia National Laboratories [5]. The flat tile mock-up was provided by the D.V. Efremov Scientific Institute in the Russian Federation as part of a US/RF ITERcollaboration.

\section{EXPERIMENT}

The mock-up consisted of four $5 \mathrm{~mm}$ thick and four $10 \mathrm{~mm}$ thick Be tiles, $1 \mathrm{~cm} \times 2 \mathrm{~cm}$ in area. Only the $5 \mathrm{~mm}$ thick tiles were tested.

To fabricate the mock-up, a block of TGP. 56 isotropic $\mathrm{Be}$ was made from hot isostatically pressed Be powder. The mating surfaces between the $\mathrm{Be}$ and $\mathrm{Cu}$ saddleblock were electrochemically polished. The $\mathrm{Be}$ block and $\mathrm{Cu}$ saddle were then mechanically clamped under $30-50 \mathrm{MPa}$ of applied pressure and placed in a vacuum furnace. The diffusion bonding occurred at $840^{\circ} \mathrm{C}$ in a background pressure of $7 \times 10^{-3} \mathrm{~Pa}$.

The Be tiles were then wire cut from the attached Be block. Each tile had two holes, $1.05 \mathrm{~mm}$ in DIA, drilled laterally to a depth of $5 \mathrm{~mm}$ to accommodate $1.02 \mathrm{~mm} \mathrm{DIA}$,sheathed, type $\mathrm{K}$ thermocouples. The top thermocouple was located $1.7 \mathrm{~mm}$ from the surface; whereas, the bottom thermocouple was $3.4 \mathrm{~mm}$ from the surface. The OFHC saddleblock was also diffusion bonded onto a DSCu (MAGT) tube measuring $1.3 \mathrm{~cm}$ in ID and $1.6 \mathrm{~cm}$ in OD. Figure 1 is a picture of this mock-up prior to testing.

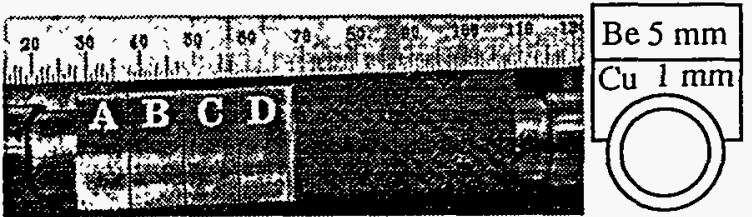

Figure 1. Flat tile beryllium mock-up

The inside of the MAGT tube contained a porous coating consisting of $100-150 \mu \mathrm{m}$ spherical copper pellets which were bonded to the inside of the tube. The purpose of the porous coating is to provide more margin for critical heat flux and enhance the heat transfer at the wall.

During the thermal response tests, the electron beam was rastered over all four tiles, A-D. They showed similar behavior to increasing absorbed heat fluxes up to 5 $\mathrm{MW} / \mathrm{m}^{2}$ producing surface temperatures as high as $300^{\circ} \mathrm{C}$. Coolant water was supplied to the mock-up at a water inlet temperature of $8-15{ }^{\circ} \mathrm{C}$, pressure of $1.4 \mathrm{MPa}$ and flow velocity of $5 \mathrm{~m} / \mathrm{s}$. The low inlet temperature was chosen to avoid the safety hazards associated with hot water-beryllium aerosols. An IR camera was used to monitor the temperature distribution across the entire mock-up.

During routine beam alignment, tile B unexpectedly debonded after only 25-30 cycles at less than $0.5 \mathrm{MW} / \mathrm{m}^{2}$. Tile A was subjected to a thermal response test up to 10 $\mathrm{MW} / \mathrm{m}^{2}$. The electron beam was rastered over the $1 \mathrm{~cm} \times 2 \mathrm{~cm}$ surface area of the tile using shot durations of $60 \mathrm{~s}$ to ensure steady state conditions in the water. A one-color, spot pyrometer was used to measure the surface temperature at the center of tile $A$.

Thermal fatigue testing was performed on tiles C and D using an absorbed heat flux of $5 \mathrm{MW} / \mathrm{m}^{2}$. Flow conditions consisted of a water inlet temperture of $12{ }^{\circ} \mathrm{C}$, flow velocity of $5 \mathrm{~m} / \mathrm{s}$ and pressure of $1.4 \mathrm{MPa}$. The low inlet temperature also allows the beryllium to be cycled below its ductile-to-brittle transition temperature. Heat flux cycle times of $15 \mathrm{~s}$ on and $15 \mathrm{~s}$ off were used. Steady state temperatures were reached in the bulk thermocouples in 10 to $12 \mathrm{~s}$ for all shots.

\section{THERMAL RESPONSE}

Figure 2 shows the temperature response of tile A measured by the pyrometer and the top thermocouple vs absorbed heat flux. The surface temperature of tile $A$ increased throughout this series, eventually reaching $690^{\circ} \mathrm{C}$ at $9.5 \mathrm{MW} / \mathrm{m}^{2}$. At $10 \mathrm{MW} / \mathrm{m}^{2}$, the tile completely detached from the copper substrate. 
No evidence of cracking or sublimation was noticed in the bulk beryllium. At its peak surface temperature near $700{ }^{\circ} \mathrm{C}$, the beryllium did experience a dramatic color

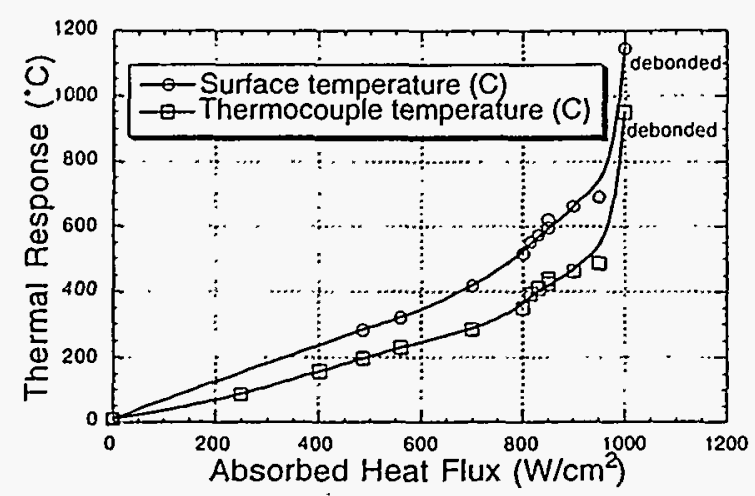

Figure 2. Thermal response of tile A.

change from a dull gray to a light silver. This may be due to the diffusion of beryllium through the surface oxide layer. The color change was very fast and occurred in 100 to $200 \mathrm{~ms}$. A post-test photograph appears in Figure 3 showing the color change on the surface and the topology of the broken bond. All top dimensions were on the order of 15 to $50 \mu \mathrm{m}$ larger than the bottom dimensions, suggesting that some plastic deformation had occurred.

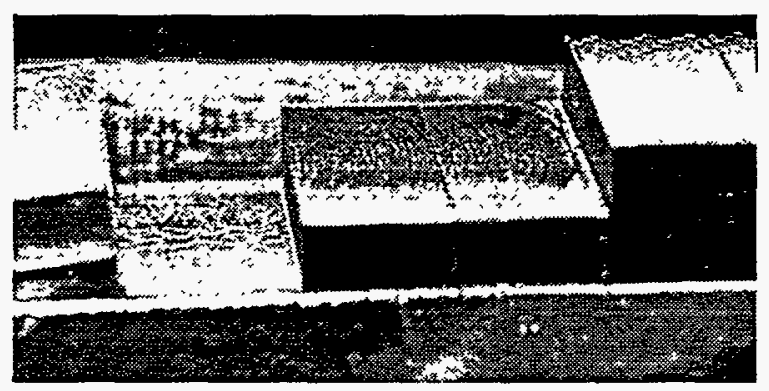

Figure 3. Post-fatigue (tile B removed)

\section{THERMAL FATIGUE}

Tile D experienced 2000 thermal cycles with no degradation in thermal response as seen in Figure 4. Visual observations of the beryllium surface were performed intermittently during the test campaign using an in situ optical borescope. No evidence of cracking or sublimation was noticed. The maximum steady state temperatures measured at the surface and in the bulk remained constant throughout the series. IR thermagraphy revealed very uniform temperature changes across the entire area of the tile indicating a uniform thermal bond.

Subsequently, the electron beam was rastered over a $2 \mathrm{~cm} \quad x \quad 2 \mathrm{~cm}$ area encompassing both tiles $\mathrm{C}$ and $\mathrm{D}$. All other conditions were identical to that for tile $D$. After 600 cycles, the steady-state temperatures on the surface of tile $D$, for example, began to gradually rise in an almost linear fashion. After 1000 cycles, the absorbed heat flux was reduced very gradually to $4.2 \mathrm{MW} / \mathrm{m}^{2}$ over the next 800 cycles to maintain constant thermocouple temperatures. At 1800 cycles, the absorbed heat flux was returned to $5 \mathrm{MW} / \mathrm{m}^{2}$. The resultant rise in temperatures was consistent with the slope of the temperature increase discovered after only 600 cycles and remained very linear afterwards. After approximately 6800 cycles, tile $\mathrm{C}$ partially debonded.

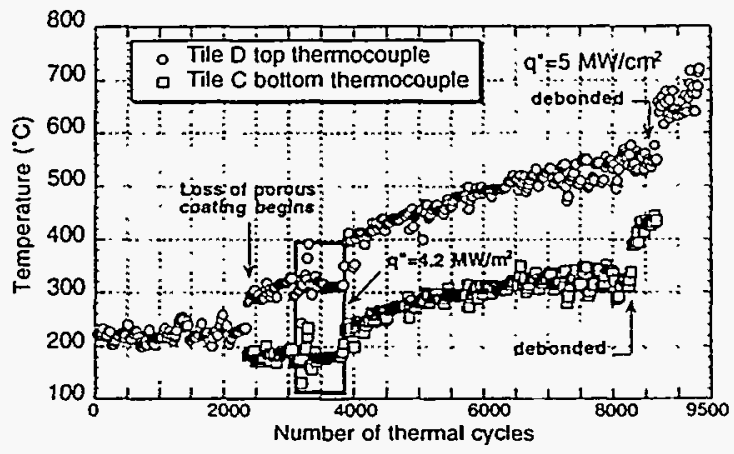

Figure 4. Fatigue behavior of tiles C and D.

Testing was continued by rastering the electron beam over the $1 \mathrm{~cm} \times 2 \mathrm{~cm}$ area of tile D only. Tile D partially debonded after an additional 400 cycles. Surface temperatures reached $1090{ }^{\circ} \mathrm{C}$ with the top thermocouple temperature near $740{ }^{\circ} \mathrm{C}$. Tile $D$ experienced a total of 9200 thermal cycles, 8400 cycles at $5 \mathrm{MW} / \mathrm{m}^{2}$ and 800 cycles between 4.2 and $5 \mathrm{MW} / \mathrm{m}^{2}$. 


\section{DISCUSSION}

The results of the thermal response tests indicate that these diffusion bonded Be tiles can easily handle a $5 \mathrm{MW} / \mathrm{m}^{2}$ heat load using $5 \mathrm{~m} / \mathrm{s}$ ambient water at $1.4 \mathrm{MPa}$.

However, the overall fatigue performance was very inconsistent from tile to tile. The gradual, temperature increase displayed by tiles $C$ and $D$ was unexpected. Post-test examination revealed no cracking of the $\mathrm{Be}$ surface. However, it was discovered that approximately $85 \%$ of the porous coating was removed from the inside of the MAGT tube under the heated areas.

It was believed that the porous coating would enhance the heat transfer by a factor of 1.5 to 2. However, ABAQUS finite element analysis revealed that a heat transfer coefficient of $10 \mathrm{~W} / \mathrm{cm}^{2}-\mathrm{K}$ was required to match the data. This represents an enhancement factor of approximately 3.3 . ABAQUS modelling of post-test data revealed a heat transfer coefficient of approximately $3 \mathrm{~W} / \mathrm{cm}^{2}-\mathrm{K}$, similar to a bare copper tube.

The linear increase in temperature was probably due to the gradual reduction in the convective heat transfer coefficient consistent with the removal of the porous coating. Growing fractures along the bond interface also could have contributed to the temperature increase. The failure mode in all cases was a rapid, unpredictable separation of the $\mathrm{Be} / \mathrm{Cu}$ joint.

The estimated shear stress at the $\mathrm{Be} / \mathrm{Cu}$ bond at $5 \mathrm{MW} / \mathrm{m}^{2}$ was approximately 35 $\mathrm{MPa}$, roughly $65 \%$ of the ultimate shear strength.

Post-test, grazing incidence $\mathrm{x}$-ray diffraction of tile $A$ revealed that two intermetallic phases existed at the bond interface, $\mathrm{Be}_{2} \mathrm{Cu}$ just under the $\mathrm{Be}$ and $\mathrm{BeCu}$ just above the $\mathrm{Cu}$ saddleblock. No $\mathrm{BeCu}$ was detected on the bottom of the tile indicating that the separation occurred within the $\mathrm{Be}_{2} \mathrm{Cu}$ layer over most of the tile surface.

This raises a critical issue of reliability, since tile $B$ debonded very quickly, while tiles
C \& D showed good adherence. The wide variation in bond strength is likely due to the brittle nature of the $\mathrm{Be}_{2} \mathrm{Cu}$ intermetallic, which was previously observed in tests at $\mathrm{JET}$ of brazed $\mathrm{Be} / \mathrm{Cu}$ actively cooled divertor mock-ups [6].

During our experiments, no degradation in the Be tiles occurred except for the possible loss of $\mathrm{BeO}$ and a related color change at temperatures near $700{ }^{\circ} \mathrm{C}$. No cracking or melting was detected. The reliability of the Be to copper joint remains a crucial issue in the development of Be clad PFCs for use in ITER. The porous coating strongly enhances heat transfer; however, adhesion is a problem.

\section{ACKNOWLEDGMENTS}

The authors would like to thank Dr. V. Sizenev, Dr. L. Gitarsky and Dr. G. Ignatovskay from CIA "Composite" for fabrication of the mock-up. The authors are also indebited to F. Bauer, K. Troncosa and L. Wold for EBTS operations.

\section{REFERENCES}

1. D.Webster and G.J. London (eds.), Beryllium Science and Technology, Vol. 1, and D.R. Floyd and J.N. Lowe (eds.), Vol. 2, Plenum Press, New York, 1979.

2. M.A. Hill, B.K. Damkroger, R.D. Dixon and $\mathrm{E}$. Robertson, "Beryllium Weldability," LA-UR-90-2516, Los Alamos National Laboratory (1990).

3. L.A. Jacobson, "Joining Methods for Beryllium - A Survey," UCID-20750, Lawrence Livermore National Laboratory (1986).

4. D.E. Driemeyer and J.R. Haines (eds.), U.S. Design Study of the ITER Divertor. Summary Report ITER/US/93/IV-PF-3, MDC 93B0044 (1993).

5. C.D. Croessmann, J.B. Whitley and G.L. Kulcinski, J. Nucl. Mater., 145-147 (1986) 410.

6. H.D. Falter et al., SPIE 1793 (1992) 162. 